\title{
Diego Fernández y Jehan Ysambart en el origen de la catedral gótica de Sevilla (1433-1434)
}

\author{
David Caramazana Malia \\ Universidad de Sevilla \\ david.caramazana.malia@gmail.com
}

El 18 de noviembre de 1433 hizo testamento Juan Martínez de Vitoria, mayordomo de la fábrica de la catedral de Sevilla y uno de los impulsores del proyecto constructivo nuevo. Este testamento ha llamado la atención de los investigadores por la manda en la que el canónigo refiere una cuenta "con Ysanbarte, cantero, et con Diego Ferrández, cantero» (Álvarez, 1990: 11-32). Si bien han sido varios los que se han ocupado de estudiar la presencia del maestro flamenco Jehan Ysambart en Sevilla (Jiménez, 2013), hasta el momento no se ha realizado ninguna aproximación al otro cantero que nombran trabajando con él, «Diego Ferrández», objetivo de este trabajo.

La primera vez que la historiografía prestó atención sobre un cantero de este nombre fue en 2007, cuando los investigadores Jácome y Antón publicaron el testamento de Andrés Martínez Tocino, jurado del concejo de Jerez de la Frontera (Jácome y Antón, 2007: 183-212). En este testamento, datado el 11 de noviembre de 1404, Martínez Tocino reconoce la deuda que tiene con los albañiles Fernán García y Diego Fernández por haber realizado su capilla funeraria en la parroquia de San Juan de los Caballeros de Jerez, conocida como «capilla de la Jura» [1].

El hallazgo de la datación de esta capilla y su conservación han permitido avanzar en el conocimiento de la historia arquitectónica de la región (Guerrero, Pinto y Mora, 2019: 1-31). Lo más interesante de la capilla de la Jura es su bóveda, la cual desarrolla unos nervios en «Y» que parten de ocho capiteles volados dispuestos en los muros y que, en su disposición en planta [2], presenta semejanzas con el esquema que Villard de Honnecourt recogió en su cuaderno del siglo XIII [3].

Volviendo sobre los artífices, Romero documentó a Fernán García, tío de Diego Fernández, ejerciendo la alcaldía del alarifazgo jerezano en 1433 (2014: 385-407) y Jiménez López halló que García y Fernández volvían a colaborar en

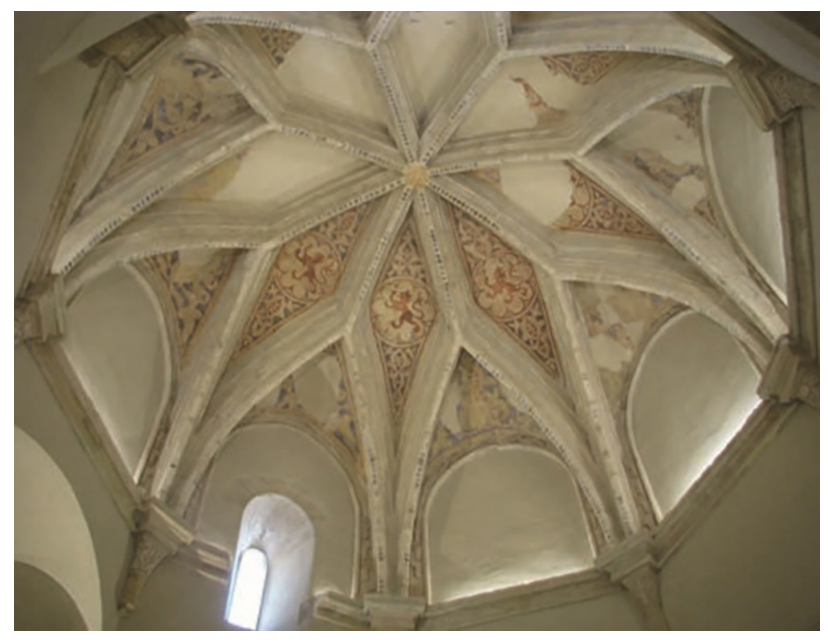

1. Capilla de la Jura, iglesia de San Juan de los Caballeros (Jerez de la Frontera). Fernán García y Diego Fernández (1404). Estado actual tras la restauración del equipo dirigido por Francisco Pinto Puerto entre 2014 y 2016

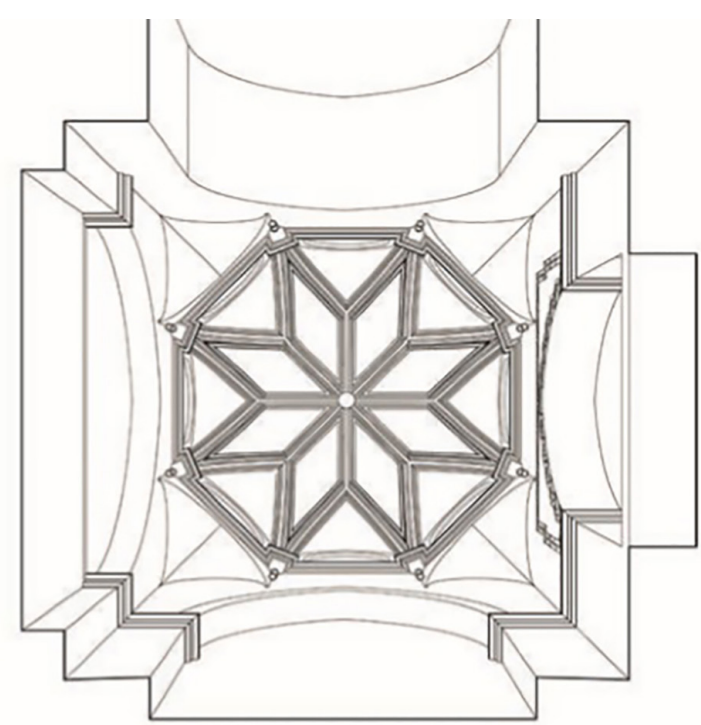

2. Perspectiva cenital de la capilla de la Jura (Guerrero, Pinto y Mora, 2019: 24) 


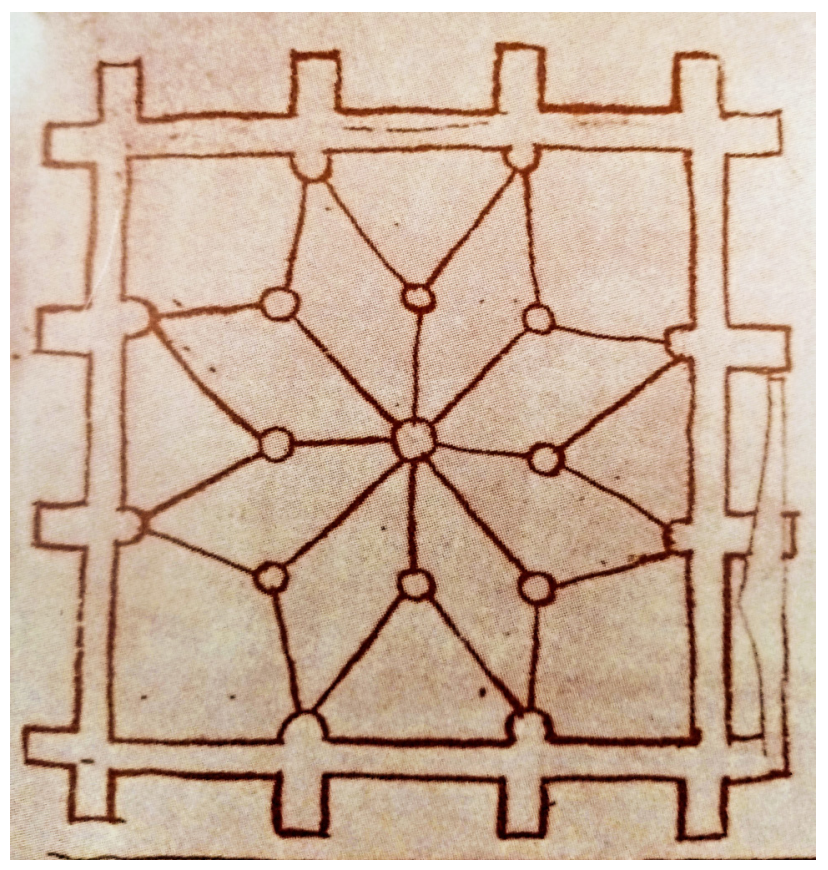

3. Lámina 41 b del cuaderno de dibujos de Villard de Honnecourt (siglo XIII) (Erlande-Brandenburg et al. eds., 1991: 135)

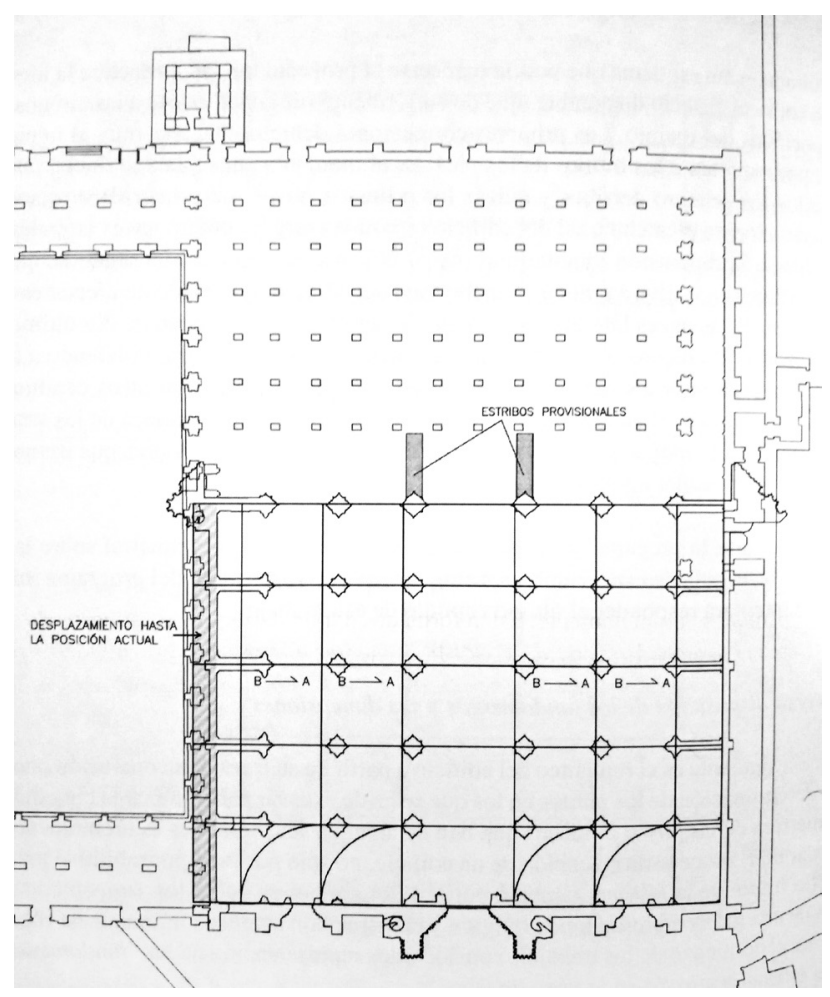

4. Hipótesis de Pinto Puerto sobre la corrección en planta del trazado inicial de la catedral de Sevilla (c. 1433) (Pinto Puerto, 2006: 238) la partición de unas casas del linaje Valdespino en Jerez en el año 1421 (2016: 139-155). Por nuestra parte, tras llevar a cabo una revisión de otras noticias publicadas sobre trabajos realizados por canteros con el nombre «Diego Fernández o Ferrández» en Sevilla, estamos en disposición de proponer una única personalidad creativa trabajando para la élite civil y eclesiástica de ambas ciudades (Jerez y Sevilla) entre 1386 y 1437.

Antes de todo, debemos señalar que Llaguno publicó una lista de artífices en donde se recoge a un tal «Diego Fernández" como uno de los «arquitectos por el Rey en Sevilla» en el año de 1373 (Llaguno, 1829: 68). Sabiendo que el cantero de nuestro estudio seguía vivo en Jerez en 1437, no parece sensato plantear una longevidad de ocho décadas y tenemos que descartar esta noticia como parte de su biografía.

Fue el profesor Martínez de Aguirre quien registró en dos momentos distintos el nombre «Diego Fernández» contratado por el concejo hispalense: entre 1386 y 1387 reforzando la muralla de la ciudad, y durante 1419 trabajando en los puentes y pasos del río Guadalquivir (Martínez de Aguirre, 1989: 21 y 1991: 14). Como decimos, seguramente el artífice que trabaja en Jerez sea el mismo, pues son estrictamente coetáneos. De ser así, Fernández habría colaborado con Alfonso Martínez, maestro mayor de la catedral de Sevilla, y con Pedro García de Sanlúcar, cantero de probable origen gaditano al servicio del concejo sevillano y que también llegó a ser maestro mayor de la catedral de Sevilla.

Con todo, es hora de retomar lo que decíamos al principio. En 1433, Diego Fernández aparece mencionado en una manda testamentaria del canónigo Vitoria sin dejar muy claras cuáles eran sus funciones en la colaboración con Ysambart, por entonces maestro mayor del rey Juan II (Torres, 1952: 265-266).

Si nos atenemos a su única obra documentada y conservada, la capilla de la Jura, a las labores que ejecutó para el concejo de Sevilla, relativas a los puentes y los pasos del río Guadalquivir, y la noticia de la partición de unas casas, podemos plantear la siguiente hipótesis: Diego Fernández, alarife de la región, sería contratado por Martínez de Vitoria como agente ${ }^{1}$ para informar del plan de traída de la piedra de las canteras de San Cristóbal por el río Guadalquivir hasta la torre del Oro, medio esencial para minimizar los costes del transporte durante la construcción de la catedral gótica (Rodríguez, 1998). 
Por su parte, cabe plantearse si Ysambart, ostentando el cargo de maestro mayor de Juan II, habría sido enviado por el propio monarca para reconocer el estado del proyecto de la catedral gótica y trazar una nueva capilla Real, permitiendo así el avance de los trabajos de reconstrucción en la zona oriental del templo (Ortiz de Zúñiga, 1677: 309-312). Esta deducción parte de su corta estancia en la sede, pues para el 7 de julio de 1434, un año después, el cabildo mandó librarle 150 maravedís «para ayuda de la costa para el camino e por los días que a estado» (Jiménez, 2006: 51). Al igual que ocurrió con la petición del cabildo de Zaragoza para que revisara con el maestro Carlín el cimborrio de la catedral (Ibáñez y Criado, 2007: 80), la documentación de Sevilla vuelve a dibujar a Ysambart como especialista en examinar la evolución de los proyectos y el estado de las obras. En este caso, con el asesoramiento de Diego Fernández, emitiría un informe para que el monarca aceptara el derribo de la antigua capilla Real y, quizás, trazase el proyecto definitivo o, con mayor certeza, interviniese en las correcciones en planta que se han registrado en la parte occidental del templo [4] (Pinto, 2006: 211-295).

A modo de conclusión, nos parece apropiado recordar que nos encontramos ante un procedimiento común en las grandes empresas arquitectónicas de los reinos hispánicos durante la Baja Edad Media, a saber: la llegada de maestros extranjeros que diseñan proyectos en concordancia con los estilos internacionales, y la aportación de los artesanos de la región, los cuales determinan las peculiaridades constructivas de la zona.

\section{Notas}

1 El agente era un intermediario que velaba por los intereses económicos de la catedral de Sevilla comprando la piedra de la sierra de San Cristóbal y resolviendo los posibles conflictos. Sobre la figura del agente, véase: Romero y Romero, 2017: 37.

\section{Bibliografía}

ÁLVAREZ MÁRQUEZ, María del Carmen (1990), «Notas para la historia de la catedral de Sevilla en el primer tercio del siglo XV», Laboratorio de Arte, n. ${ }^{\circ}$ 3, pp. 11-32.

GUERRERO VEGA, José María, PINTO PUERTO, Francisco y MORA VICENTE, Gregorio (2019), «Trabajos previos y paralelos integrados en el proyecto de restauración de la capilla de los Tocino (s. XV) en la iglesia de San Juan de los Caballeros de Jerez de la Frontera”, Arqueología de la Arquitectura, n. ${ }^{\circ}$ 16. DOI: https://doi.org/10.3989/arq.arqt.2019.008.

IBÁÑEZ FERNÁNDEZ, Javier y CRIADO MAINAR, Jesús Fermín (2007), «El maestro Isambart en Aragón: La capilla de los Corporales de Daroca y sus intervenciones en la Catedral de la Seo de Zaragoza», en JIMÉNEZ MARTíN, Alfonso (ed.), La piedra postrera. V Centenario de la conclusión de la Catedral de Sevilla, vol. 2, Sevilla, pp. 75-113.

JÁCOME GONZÁLEZ, José y ANTÓN PORTILLO, Jesús (2007), «La capilla de "la Jura” de San Juan de los Caballeros, de Jerez de la Frontera: entre la épica y la realidad histórica», Revista de Historia de Jerez, n. ${ }^{\circ}$ 13, pp. 183-212.

JIMÉNEZ MARTíN, Alfonso (2006), «Las fechas de las formas. Selección crítica de fuentes documentales para la cronología del edificio medieval», en AAW., La catedral gótica de Sevilla. Fundación y fábrica de la obra nueva, Universidad de Sevilla, Sevilla.

- (2013), Anatomía de la Catedral de Sevilla, Diputación de Sevilla, Sevilla.

LLAGUNO Y AMIROLA, Eugenio (1829), Noticias de los arquitectos y arquitectura de España desde su restauración. Ilustradas y acrecentadas con notas, adiciones y documentos por Juan Agustín Ceán Bermúdez, Madrid.

MARTÍNEZ DE AGUIRRE, Javier (1989), «Notas sobre las empresas constructivas y artísticas del Concejo de Sevilla en la Baja Edad Media», Laboratorio de Arte, n. ${ }^{\circ}$ 2, pp. 15-32.

- (1991), «Notas sobre las empresas constructivas y artísticas del Concejo de Sevilla en la Baja Edad Media: 1370-1430 (y II)», Laboratorio de Arte, n. ${ }^{\circ}$ 4, pp. 11-28.

ORTIZ DE ZÚÑIGA, Diego (1677), Anales eclesiásticos y seculares de la muy noble y muy leal Ciudad de Sevilla, Sevilla. 
PINTO PUERTO, Francisco (2006), «Fábrica y forma del templo gótico», en AA. W., La catedral gótica de Sevilla. Fundación y fábrica de la obra nueva, Universidad de Sevilla, Sevilla, pp. 211-295.

RODRíGUEZ ESTÉVEZ, Juan Clemente (1998), Los canteros de la Catedral de Sevilla: del Gótico al Renacimiento, Diputación de Sevilla, Sevilla.

ROMERO MEDINA, Raúl (2014), «Los Rodríguez: una saga de maestros constructores a finales de la Edad Media en Jerez», en BAREA RODRÍGUEZ, Manuel Antonio y ROMERO BEJARANO, Manuel (coords.), 750 Aniversario de la incorporación de Jerez a la Corona de Castilla: 1264-2014, Patrimonio, Jerez de la Frontera, pp. 385-407.

ROMERO MEDINA, Raúl y ROMERO BEJARANO, Manuel (2017), «La obra tardogótica de la Cartuja de la Defensión de Jerez de la Frontera. Reflexiones sobre la intervención de Diego de Riaño», De Arte, n. ${ }^{\circ}$ 16, pp. 31-48.

TORRES BALBÁS, Leopoldo (1952), «Arquitectura gótica», en AA.W., Ars Hispaniae: historia universal del arte hispánico, vol. VII, Madrid, pp. 265-266. 